\section{INTRODUCTION OF BARTON CHILDS}

It is my great pleasure to introduce the recipient of this year's Colonel Harland Sanders Award for lifetime achievement in genetic research and education, my colleague, mentor and friend-Barton Childs.

Barton was born in Chicago in 1916, some 83 years ago. He grew up in the mid-west and attended Williams College, graduating in 1938. He enrolled that same year in the Johns Hopkins University School of Medicine, beginning an affiliation that has now gone on for more than 60 years, interrupted only by two and a half years of active duty on the battlefields of Europe during World War II and a stint at the Galton Labs in the early 50 's.

Figure 1 shows Barton and his fellow house officers standing on the steps of the Harriet Lane Home for Invalid Children during his internship in Pediatrics in 1942. I chose it not only to show a younger version of Barton but also because standing in front is the then Chairman of Pediatrics, Dr. Edwards A. Park. Dr. Park had a great influence on the development of American pediatrics. More to the point for today's award, Dr. Park had a great influence on Barton. In fact, Barton has told me on more than one occasion that among the many distinguished scientists, geneticists and scholars he has known, Dr. Park was the "only truly great man."

Of the many Park anecdotes I have heard from Barton, one in particular seems relevant today. Barton described standing in a hallway in the Harriet Lane Home as a young house officer when Dr. Park strode up, literally grabbed Barton by the ear and dragged him outside to look at a Peregrine falcon perched on a nearby window sill-literally forcing Barton to observe one of the great achievements of genetics and evolution.

In a similar way, I believe that Barton's greatest contribution over the last 60 years is that he has grabbed so many of us by the ear and forced us to think about genetics and the role our genes play in health and disease.

A sense of this commitment to genetics and education can be obtained from a review of his publication record. Like other outstanding human geneticists of his time, his work includes important observations on hemoglobinopathies, red cell enzymopathies, and amino acid disorders-nearly all stemming from thoughtful study of patients with some sort of genetic variation. One of the most salient of these appeared in contributions in the 1963 Proceedings of the National Academy of Science USA. Two years earlier, Mary Lyon had proposed her famous hypothesis for dosage compensation of genes on the $\mathrm{X}$ chromosome. In this paper, Barton and colleagues used the $A B$ variant of the $X$-linked G6PD to show that Mary Lyon's hypothesis was indeed correct in humans (Figure 2).

More striking, however, than these outstanding scientific contributions is that, from the very beginning, Barton has

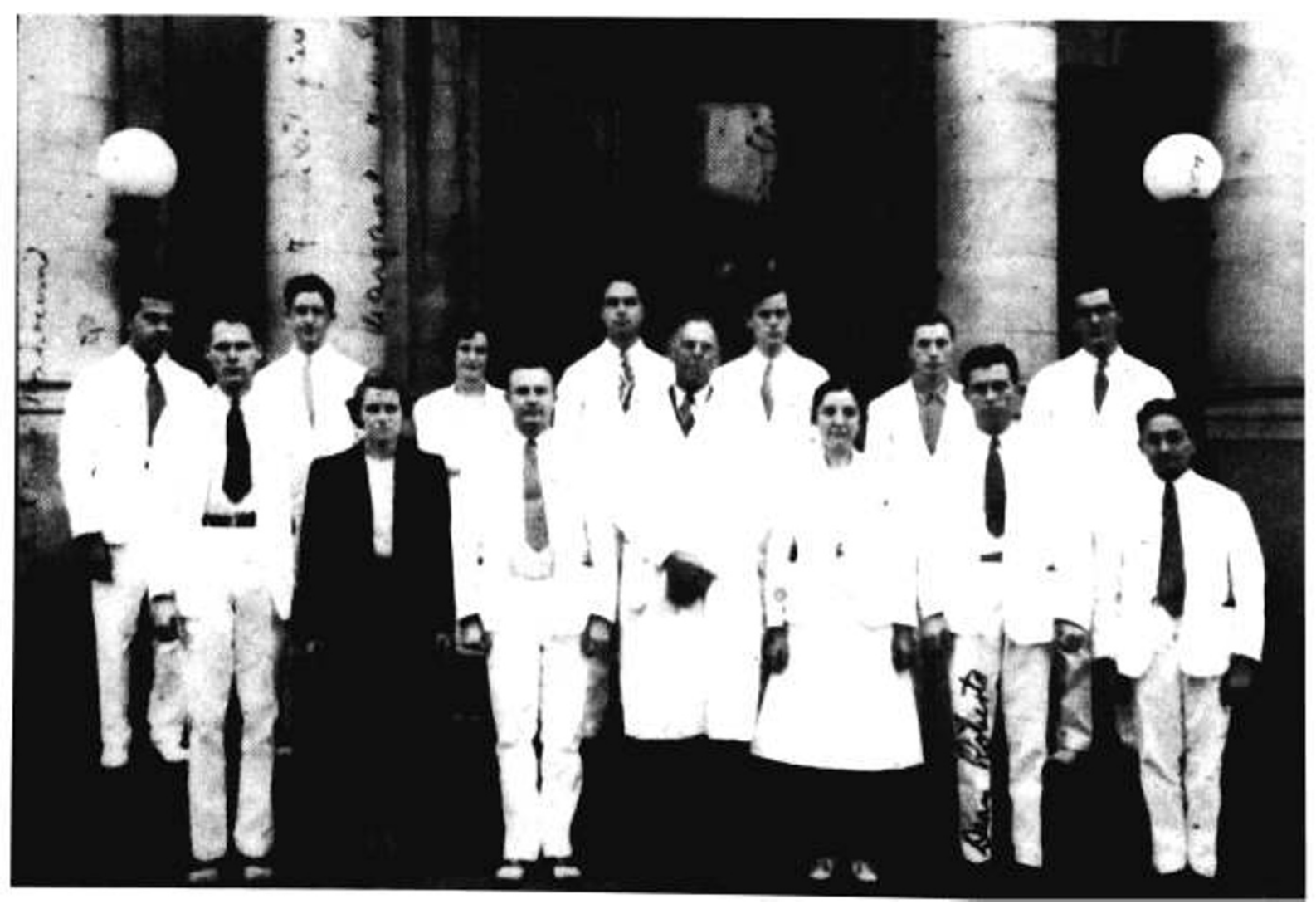

Flg. 1 The house staff of the Harriet Lane Home of the Johns Hopkins hospital in 1942. Barton Childs is the 5TH from the left in the top row. Dr. Edwards A. Park is $4 \mathrm{rH}$ from the left in the bottom row. 
been thinking deeply about genetics, how to integrate genetics with medicine and how to educate the rest of us about the value and necessity of this approach. For example, included in his publications in the early to mid 50's are papers on:

- The influence of heredity of the health of the family

- Constitutional factors in obesity

- Genetics in pediatric disease

- A survey of genetics as it applies to medicine

Remarkably, over the years Barton has continued, even accelerated, his efforts to "grab us by the ear" and show us the role of genetics in medicine. In the last few years, his publications include papers on the genetic basis of Crohn's disease, ulcerative colitis, benign prostatic hypertrophy and prostatic cancer, dyslexia, schizophrenia, and other psychiatric disorders. This published work represents only the tip of the iceberg of his efforts to get us to think genetically; most of his waking hours are devoted to this end. Let me illustrate his determination of purpose with one more anecdote from a couple of years ago.

Barton was in the parking garage on his way in to work in the morning when he met an old Hopkins colleague, an adult cardiologist. After the usual anxious moments as each struggled to recall the other's name, the cardiologist began a lament about how many of their colleagues were succumbing to various forms of cardiovascular disease-concluding by saying he couldn't understand why so many had problems of this sort and wondering if it had something to do with modern lifestyles and diets. Barton, always alert for an opportunity to educate, responded with "You don't suppose it could be in their genes." The cardiologist, dumbstruck by the epiphany, replied "Gee, I never thought about that."

One of the great good fortunes of my own career has been to be able to interact with Barton on at least a weekly basis for many years. The discussions have been wide ranging and for me, at least, always enriching and exhilarating. Thankfully, for those of you not so fortunate, he has just completed putting many of his ideas on paper and they will soon appear in a book to be published later this year by the Johns Hopkins University Press. ${ }^{1}$ I recommend it to all of you.

I'll close with this image of Barton at a recent birthday party (Figure 3). He was born on leap year day so in fact in this picture, he is only a little more than 20 years old. The cake was given to him by our graduate students who revere him, as I do, for his wisdom, his intellectual rigor, his humility, and for his unending commitment to educate us all.

David Valle, $M D$

\section{BARTON CHILDS' STATEMENT}

I've been told that I may have 15 minutes or so to say something about my career. Nothing could be more boring to me so I prefer to say something about what a long career has allowed me to observe. I refer to a rapprochement between medicine and society. I don't mean abuses like HMOs and the idea of medical care as a commodity. I do mean changes in the medical mentality stimulated by genetics.

Fifty years ago as Director of Outpatients in Pediatrics at Hopkins, I observed many children afflicted by anomalies of

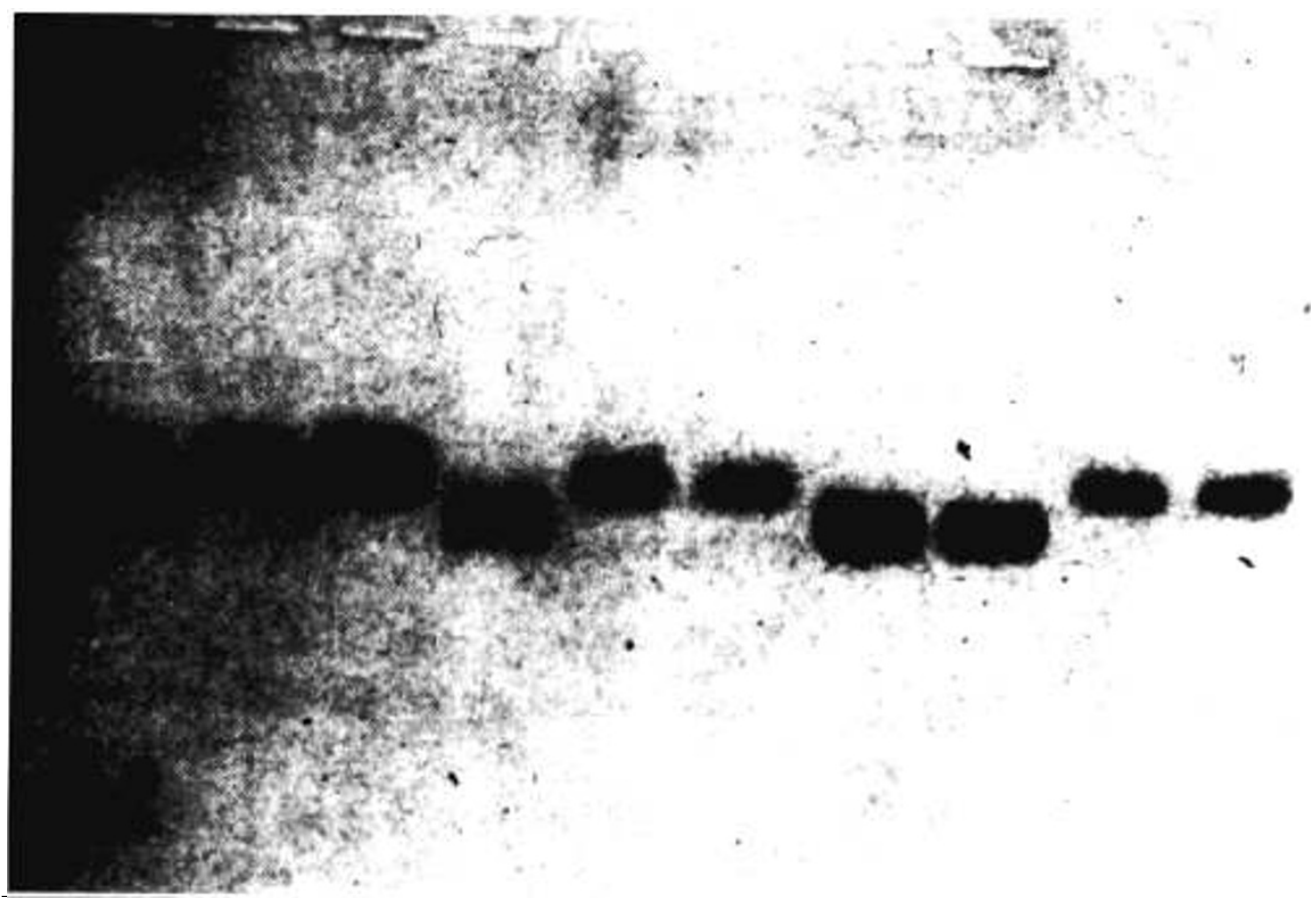

Fig. 2 A starch gel electrophoresis of G6PD isozymes shown in Figure 2 of the paper "Demonstration of two populations of cells in the human female heterozygous for glucose-6-phosphate dehydrogenase variants" by Ronald G. Davidson, Harold M. Nitowsky, and Barton Childs communicated by Theodore T. Puck to PNAS 50:481-485, 1963. The left hand lane shows the AB pattern in a mixed population of cultured skin fibroblasts from "Mrs. De." The lanes to the right show the pattern in 9 clones derived from the original cell line. There are $6 \mathrm{G} 6 \mathrm{PD} \mathrm{B}$ (slow) clones and $3 \mathrm{G} 6 \mathrm{PD}) \mathrm{A}$ (fast) clones. 


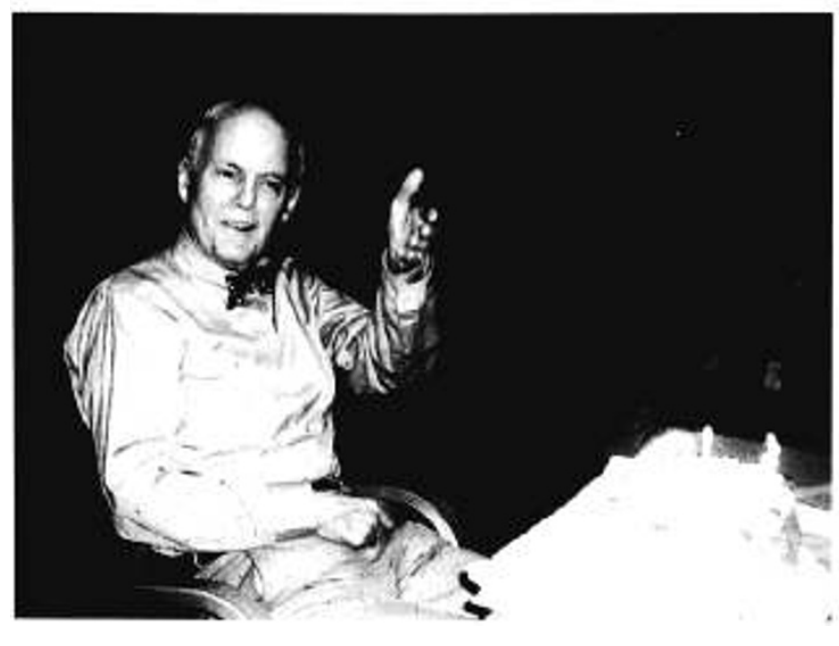

Fig. 3 Barton at a recent hirthday party.

development. I'm sure I had no less concern for these unfortunate children, nor any less engagement in their care than any pediatrician ought, but I perceived them as something apart. To start with, they were called anomalies, a word based on the Greek for "not the same," and then the study of anomalies was called teratology deriving from teratos, Greek, for monster. Indeed some medical texts still referred to the malformed as monsters. So my insensitivity reflected my education in the medicine of the time. Medicine was then an autonomous enterprise, acknowledging obligations to individuals as patients, but little to their lives as social beings. For example, consent was obtained for surgery but it was hardly informed, while experiments were done without any consent at all. Indeed patients and their relatives seemed to have no rights, and those who claimed them were said to be interfering. What they thought was of no interest! These things are all changed now; social mores have changed; and some of the differences are owing to how genetics has moved into medicine, and I wish to speak of them. But first-the position of genetics in the 1950's.

Casting about for some way to study these developmental problems, I hit upon genetics and then found the Galton Laboratory at University College in London as the place to go. Naturally, I was enthusiastic about my decision and told friends about it, but the idea was so regularly greeted by incredulous stares that I soon disguised my purpose.

At the Galton I met Lionel Penrose, Harry Harris, J. B. S. Haldane, and others. Paper chromatography for the separation of amino acids and paper electrophoresis to separate serum proteins represented the high technology of the time. Blood group differences were the most informative phenotypes then, while cytogenetics had not yet taken off; 48 was still the chromosome number. Counseling, screening, testing, risk factors didn't exist.

All this may sound pretty Neanderthal to you, but the 40's and early 50's were a defining moment for genetics; Beadle and Tatum in 1941; Avery, McLeod, and McCarty in 1944; and Watson and Crick in 1953 made this a stimulating time to enter a career in human genetics. Penrose's work with PKU and Harris' demonstration of the power of chemical analysis to detect genetic heterogeneity, evoked the heritage of Archibald Garrod, which pervaded the Galton. But Penrose was thinking of other things too. It was he who changed mongolism to Down's Syndrome. "They're not mongols," he would say, "they're British!"

Now make the dizzying leap to our meeting in Miami and observe that the program emphasizes the reduction of phenotypes to molecular variants of proteins specified by genes, proteins that maintain the integrity of open systems, and, in the form of variants that fail in their homoeostatic roles, they have become the central focus of pathogenesis. Indeed disease can be defined as a consequence of incongruence between a molecularly vulnerable homeostatic apparatus and experiences of the environment.

But the program of the meeting reveals other concerns too: questions of informed consent, confidentiality, education, counseling, testing and screening, risk factors, discrimination by insurers or employers, and the law. These engage habits, customs, and social behavior, and at first glance these issues seem utterly foreign to, and not to be comprehended within, the prevailing reductive model. But in fact they are integrated. They derive no less than diagnosis and treatment from these variant unit steps of homeostasis.

Philosophers of science take an Olympian view of biology, seeking some basis for all biological generalizations, including evolution, in molecular terms. The view from above is, of course, of integration, so the philosophers are concerned with theories of unity. But how do the Olympians see integration between gene-induced phenotypes and their inverse social origins and meanings? The common ground is the molecular individuality that characterizes disease phenotypes (Figure 4). The arrows on the left connect this individuality with that of the disease by way of biochemical, physiological and clinical properties. Those on the right describe the individuality that must enter into social decisions called for by the attributes of the disease. The arrows point up from molecular individuality through population genetics, including polymorphism, and the frequency, ethnicity, and distribution of genes, to natural selection. The latter works through variation in the environment, especially cultural which, in turn, evokes the logic of disease prevention, which, as we know, brings in it's wake, unexpected complications, themselves a consequence of a clash between the logic of biology and that of cultural and social organization. These complications are those I've mentioned, and all were foreign to the genetics of the 1950's.

So these complications are a consequence of genetic and molecular individuality. Most such molecules compose structures and competencies that qualify as normal, while others represent degrees of homeostatic fragility contributing provisionally to risk to health. I say provisionally because the degree of risk, while residing originally in the variant proteins acting as proximate cause, is actually determined by several factors of which the compensatory powers, or lack thereof, of other relevant aspects of homeostasis is one, the quality, intensity, and 


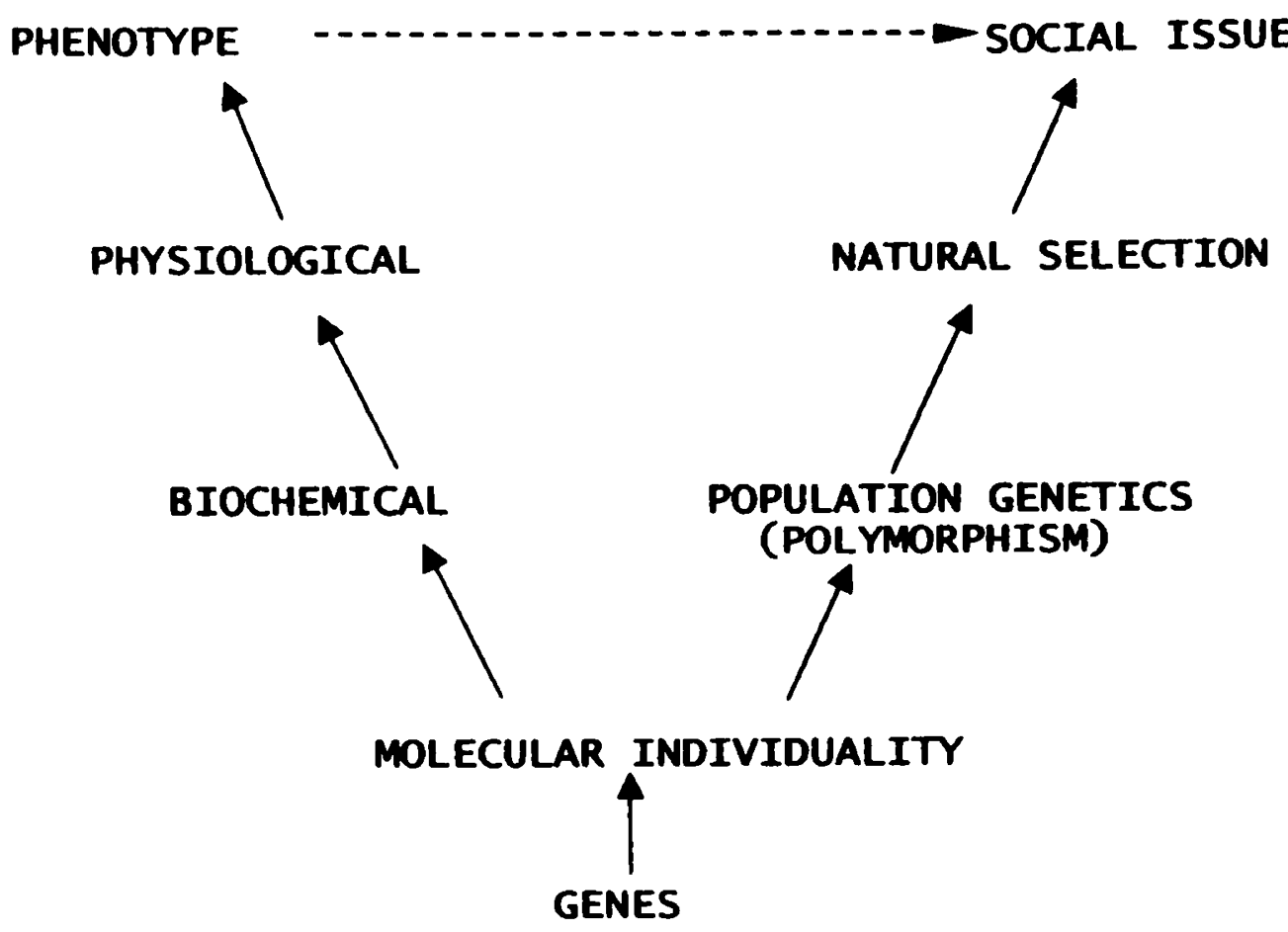

Fig. 4 The social issues arise from molecular individuality no less than the phenotype.

duration of experiences that bear affinities for the variant unit steps are a second, and a third is the metabolic matrix in which interactions take place and which changes along a trajectory determined by development, maturation, and aging. And since each such matrix is, by definition, unique, the effect exerted by the product of a given allele is variable. It is these qualities that engender questions of fine tuning of preventive measures, of specificity and sensitivity of tests and of their meaning to individuals, of population screening for traits and genes, of the particularity of counseling and concerns about confidentiality, insurance, and public education. What a difference a few decades have made, not only in the sensitivity of the counselor to the hopes and fears of individual patients, but in how medicine has accepted new responsibilities and in various ways promulgated new rules for handling new problems. But there's more to come.

The Human Genome Project will add to the lore of human molecular individuality, exacerbating the need for reconciliation of the biological and social sides of molecular individuality. So the medicine of today, far from autonomous as it once was, is as deeply embedded in society as religion or education.

This recognition of associations between epidemiologically defined risk factors and gene differences seems to me to be the first step in a sea-change in medical thinking. We can perceive disease as residing in the specificity of unit steps of homoeostasis for particular aspects of the culture, or, we can see it as residing in the way the culture is organized. If we are motivated by the first perception we will do our best to apprize our patients of the elements of their particular susceptibility and suggest that they change some aspect of their lives, and that we can count as fulfillment of our responsibility. But the logic of the second path, compels us to go beyond advice to individuals to persuade the public and to participate with government to change the threats. But, of course, the March of Dimes has been doing that since its inception. And so has the American Heart Association, The American Cancer Society, The American Academy of Pediatrics, all the many disease related societies, and the various arms of the Public Health enterprise, government too, in the form of FDA, OSHA and state and city health departments. But all of these are agencies to which the individual physician can cede responsibility, reserving for her or himself that of advising patients to avoid what society continues to approve, no matter how injurious to how many vulnerable citizens. I suggest that it is because so many physicians see their responsibility thus that the AMA, which is our representative, has been more concerned with autonomy than with intercession. For example, it is lawyers who have tried to make the tobacco industry accountable, not physicians. Evidently we still have some consciousness-raising to do among physicians whose mentalities are not yet geneticised. I'm not suggesting action by individual physicians here, but the sense of responsibility that promotes action.

We all agree that the discovery of the nature, the number and the function of the genes of so many organisms is one of the most remarkable attainments of the $20^{\mathrm{TH}}$ century. I suggest that its complement, the conditions of the environment that constitute the risk ought to be the goal of an equally well supported and vigorous effort in the $21^{\text {sT }}$ century. It will have to be a different kind of epidemiology, one that acknowledges 
the variations of individuals within populations, as well as those of individual developmental trajectories, since what we are as adults is an outcome of what we were in early life. The aim would be to couple molecular individuality with the kinds, intensities and duration of experiences that lead to disease, with the purpose of rearranging both individual lives and social organization in such a way as to raise the heritability of disease in the direction of 1.0 , leaving the residual, intractably genetic problems to the gene therapists. If this sounds complicated, impossible, or absurd, so perhaps did the Genome Project before we began to take it seriously.

So, in conclusion, molecular genetics shows that my sense of the malformed as something apart was simply ignorance, and we all know how dangerous ignorance is. There are no biological discontinuities among human beings, all are a part of the main, and beliefs to the contrary are socially constructed. Molecular individuality also evokes a logic of prevention. Both of these concepts represent an intertwining of medical and social purpose that no one foresaw when I started in genetics. It's been deeply satisfying, however unpredictable. But that sense of progress, even if unanticipated is just what has made my career so fulfilling to me. My hope for others is that they will experience the same satisfaction in helping to cope with the unforeseeable events that lie before us all.

Barton Childs, MD

\section{References}

1. Childs B. Genetic medicine: A logic of disease. Baltimore: Johns Hopkins University Press, 1999

Presented during the 1999 Ammal Clinical Genetics Meting, sponsored by the Antericin College of Medical Genctics in Cooperatron with the 3 oth Anmual March of Dimes Clmial Gintics Conferenci

Dr. Burtum (hilds is currently Professor Fimeritus in the Department of Pediatrics at the Johns Hopkins L'miersity School of Medicine, Baltimorc, Maryland. Dr. David V'alle is currently Professor of Pedutrics and Molectular Biology E- Genethes at the sume institution. 